few pains the head descended to a little below the level of the spines, where for nearly an hour it seemed to remain stationary. The labor pains were distinctly not of the usual second stage type, and pituitary extract was without effect. An anesthetic was administered and the patient was delivered by a comparatively easy forceps operation. The baby was a perfectly formed female child weighing $3,960 \mathrm{gm} .(83 / 4$ pounds), and $50 \mathrm{~cm}$. (197/10 inches), in length. The face showed marked edema and passive congestion, and the hear seemed fixed in extreme extension. Aside from a slight abrasion on the right temple, the skin and muscles of the face and neck appeared normal. There was no suggestion of hematoma at any point. The attitude of the head seemed fixed, no matter in which position the infant was placed.

The puerperium was uneventful, and the edema and congestion of the face cleared up entirely in a few days. The extreme extension of the head, however, persisted, and as in the case reported by Morse, any attempt to flex the head seemed to make the child very uncomfortable. This degree of extension persisted for the entire first month of life After this the child seemed to hold its head in a less extended position, and when 3 months old the condition approximated normal, although there was some tendency for the head to fall back in extension when the child was held upright.

It seems reasonable to believe that not only may continued extension of the fetal head in utero cause this deformity, but as in the case here reported, continued extension during a long labor may produce the same result.

419 Temple Strcet.

\section{A CASE OF IMPASSABLE ESOPHAGEAL STRICTURE}

Anthony Bassler, M.D., New York

Clinical Professor of Medicine, New York Polyclinic Medical School

The following case is of interest because of the age, the poor results accomplished by operation, the reasons why, and the medical things devised in the case which may be of help to others.

History.-H. O., boy, aged 3, came under observation, June 25, 1913. Seven weeks before that time the mother was making soap, the child being with her in the same room. The child, taking advantage of the mother's absence from the room for a few minutes, took a mouthful of the mixture and swallowed it, his mouth and lips being badly burned by the caustic lye. For three days he could take only small quantities of fluid, the mouth being too sore to masticate foods. During these three days he vomited several times, and complained of a burning sensation in the region of the cardia. Four weeks after that he contracted measies, at which time the attending physician noticed that he could not swallow well. This dysplagia increased until finally he could not swallow the smallest quantity of fluids. During the two or three weeks before coming under observation he had little, if any, food, and in the last two or three days, after an hour's time trying, not a particle of milk would go down.

Opcration and Result.-On examination an impassable stricture about on a level with the arch of the aorta was encountered. The child being very much reduced from starvation, operation was decided on, and performed by $\mathrm{Dr}$. Grant in the New York Polyclinic on the following day. An opening was made into his stomach. A No. $18 \mathrm{~F}$. olive could be passed from below through the stricture, but not from above downward. Abbe's string-cutting method was employed until a No. 34 F. could be passed from below up. The operation was terminated by gastrostomy for feeding, and a heavy braided surgeons' silk extending from the mouth to the gastrostomy opening. The child fed for several days through the gastrostomy opening. On the fourth day an effort was made to pass a tunnel bougie down the string, both ends being held taut; some resistance at the site of the stricture was encountered, allowing only a $28 \mathrm{~F}$. to go through. Four or five days after this the child chewed the string, making impossible the passage of tumnel bougies unless another string was introduced.
At that point the troubles began, the child being old enough to have some sense and resist, and still not being old enough to be controlled mentally; gradually the stricture closed, and in three months' time following the operation an $18 \mathrm{~F}$. olive could no longer be passed through it. During this time he was fed through the gastric fistula. Efforts were made to have him swallow a string. Twice he was anesthetized and a string introduced from his mouth into his stomach, but he immediately proceeded to chew the end in his mouth, cutting it in a short time. A special sound was made, having a long tapering point, the shaft being No. $25 \mathrm{~F}$. Numbers of efforts showed that only the point of the sound could be made to pass the stricture. A very small sound was made with a bag attachment, which, after a number of trials, was passed through the stricture, the bag inflated from above first by means of air and then by means of water. These dilations were made with the bag below the stricture, efforts being made to pull it through, and with the bag at the site of the stricture, in the hope of dilating it at right angles, neither of which devices was successful. At the end of a year's time the stricture would permit of the passage of only a $20 \mathrm{~F}$. olive. The difficulty in using a larger size was because of the irregularity of the caliber of the stricture, it being impossible to get a string through and control the boy from biting its upper end. At this time the child could swallow small quantities of fluid, but no semisolids or solids. Difficulty was also encountered in keeping the gastric fistula open. This became so acute that it was decided to allow it to close, taking chances with what could be done from above. The operation plainly was not a success, so far as giving permanent results in enlarging the stricture. Success was accomplished by the following:

Successful Procedure.-Giving the child a teaspoonful of olive oil to swallow, wrapping him up in a blanket so that he could not fight with his hands and feet, putting in a mouth gag of the form used in O'Dwyer's intubation set, with the clild's body flat and the head extended in a typical gastroscopy position, and about three people to hold him, a filiform whalebone of the kind used to pass a prostatic stricture was passed into the stomach, the upper end of the filiform held by a nurse. On this filiform, which is a yard in length, funneled bougies were run through the stricture, gradually increasing it in size in a year's time, so that a No. $35 \mathrm{~F}$. could be sent through. At a number of the times after passing a fairly large sized olive, elastic esophageal sounds were used, allowing the largest possible to get through and remain in the esophagus for some minutes.

At the present time the child requires to have the stricture kept open by dilation about once every eight wceks, and he is perfectly well, being able to swallow anything. By constant instrumentation, and according to the feeling, the stricture is not only enlarging in caliber, but also is not so dense as it was.

21 West Seventy-Fourth Street.

A Modified Bronchoscope Pump.-In operating with the aid of a bronchoscope, a clear and unobstructed field is almost indispensable. Frequent sponging with cotton or gauze not only retards the operator, but also frequently results in injury to the delicate mucous membrane. The sponges sometimes become detached from the holders, and their recovery is frequently a difficult and tedious task. During the past year I have in a measure overcome these difficulties by the employment of a suction pump, with 3 feet of snall rubber tubing attached. The free end of the tube is connected with the base of an ordinary ureteral catheter, which is then placed inside the barrel of the bronchoscope. The diameter of the catheter is so small that it offers practically no obstruction, and a few strokes of the pump will serve at any time to clear the field of mucus and blood. While the method may not be a new one, I have never seen it suggested, and as it has proved so satisfactory in my hands, I trust that it will be of benefit to others.-CharLes W. Gosney, M.D., Kansas City, Mo. 